\title{
A tuberculose no cotidiano médico e o efeito bumerangue do abandono
}

\author{
Tuberculosis in day-to-day medical practice \\ and the boomerang effect of neglect
}

Lia Selig ${ }^{1}$

Kátia Geluda ${ }^{2}$

Túlio Junqueira ${ }^{1}$

Rossana Brito ${ }^{3}$

Anete Trajman ${ }^{4}$
${ }^{1}$ Fundação Serra dos Órgãos. Av. Alberto Torres 111, Alto. 25964-004 Teresópolis RJ.

lia.selig@gmail.com ${ }^{2}$ Sociedade Brasileira de Psicanálise

${ }^{3}$ Secretaria de Estado de Saúde e Defesa Civil do Rio de Janeiro

${ }^{4}$ Universidade Gama Filho

\begin{abstract}
The scope of this study was to understand the perceptions and feelings of physicians dealing with tuberculosis (TB) in Rio de Janeiro. Eleven physicians working in a large public hospital were interviewed using a semi-structured questionnaire. The interpretation of the interviews was based on hermeneutic-dialectic phenomenology. The answers were analyzed in order to identify and understand their live TB-related experiences from their statements. Among the categories that emerged, neglect was chosen as the focus of this article in its four dimensions: respect, responsibility, conditions of care and discomfort. The boomerang effect of neglect was perceived during interviews with physicians: the one who neglects is also neglected. Other reported feelings included lack of motivation, anger, and frustration. The mental health of physicians is a preoccupation because of overwork in inadequate conditions. The question that arises is how health staff working in such environments can adequately care for their patients. We conclude that in order to achieve TB control as well as other health system goals, human resource policies that respond to physicians' job needs should be implemented.

Key words Health policy, Working conditions, Professional burnout, Delivery of health care, Tuberculosis
\end{abstract}

Resumo O objetivo do estudo foi conhecer a percepção e os sentimentos dos médicos sobre a tuberculose (TB) no Rio de Janeiro. Onze médicos de um hospital público de grande porte foram submetidos a uma entrevista semiestruturada. O processo investigativo teve como base a fenomenologia hermenêutica-dialética. As falas dos depoentes foram analisadas com o objetivo de identificar e compreender no seu discurso suas vivências sobre o seu viver-ser-estar-adoecer que estivessem relacionadas à TB. Dentre as categorias identificadas, o abandono foi abordado neste artigo em suas quatro dimensões: o respeito, a responsabilidade, as condições de atendimento e o mal-estar. Percebese o efeito bumerangue do abandono: aquele que abandona também é abandonado. Outros sentimentos referidos foram os de desmotivação, revolta e de frustração. É preocupante a saúde mental dos médicos submetidos à sobrecarga de trabalho e em condições inadequadas. Questiona-se como cuidadores nestas condições podem exercer sua função de cuidar. Concluímos que controlar a TB bem como alcançar os demais objetivos do SUS deve envolver uma politica de recursos humanos que responda às questões apresentadas.

Palavras-chave Política de saúde, Condições de trabalho, Esgotamento profissional, Assistência à saúde, Tuberculose 


\section{Introdução}

A tuberculose (TB) acomete cerca de 70 mil indivíduos e é responsável por 4,5 mil óbitos a cada ano no Brasil. É uma prioridade do Ministério da Saúde que no período 2007-2008 investiu US\$ 120 milhões no seu controle. O Plano Global para Controle da Tuberculose - Stop TB Partnership - OMS estabeleceu metas para o controle da doença até 2015 que, para serem atingidas, obriga o país a investir não somente em estratégias conhecidas, mas também em ações inovadoras.

O óbito por TB é considerado um evento sentinela, por ser evitável e por demonstrar as falhas da rede social e do sistema de saúde ${ }^{1}$. Envolvidos com o óbito estão a percepção de doença pela população, o acesso à rede de saúde, a detecção e o diagnóstico do caso pelo sistema de saúde, o manejo clínico adequado, os recursos financeiros e a rede social que permitam ao paciente realizar o tratamento. Estão descritas intervenções relacionadas ao controle da tuberculose para cada uma destas áreas, bem como estudos sobre vivências e crenças do paciente em relação à $\mathrm{TB}^{2,3}$. São ainda amplamente reconhecidas condições de vulnerabilidade deste grupo de indivíduos e sua necessidade de empoderamento para o exercício do controle social.

Em contraste, pouco se conhece sobre o cuidador. O profissional de saúde, protagonista das ações na rede de saúde, tem sido alvo de capacitações e sensibilizações para lidar com grupos de indivíduos com dificuldades especiais, como os pacientes empobrecidos e estigmatizados. Entretanto, não se escuta o profissional. Como observado por $\mathrm{Campos}^{4}$, o profissional de saúde precisa não apenas prescrever, mas cuidar. A condição para executar esta tarefa não é fruto apenas de capacitações. Para cuidar, é necessário ser cuidado ${ }^{4}$.

Com frequência, os médicos apresentam sinais e sintomas compatíveis com o sofrimento psíquico, entre eles, a síndrome do burnout (SB) - síndrome do esgotamento profissional ${ }^{5}$. Para Trigo et al. ${ }^{6}$, "burnout é definido, segundo um jargão inglês, como aquilo que deixou de funcionar por absoluta falta de energia. Metaforicamente, é aquilo, ou aquele, que chegou ao seu limite, com grande prejuízo em seu desempenho físico ou mental".

A síndrome é consequência da interação de características individuais, ambientais e do trabalho que propiciam exaustão emocional, distanciamento afetivo e baixa realização profissional ${ }^{5}$. É possível que sensibilização e capacitação, essenciais para o cuidado médico, tenham baixa efetividade em grupos que vivenciam a síndrome do esgotamento profissional. O objetivo do presente estudo é o de identificar e compreender, no discurso dos médicos que assistem ao doente com TB, suas vivências sobre o seu viver-serestar-adoecer que estejam relacionadas à TB.

\section{Método}

\section{Concepção teórica}

O investimento em intervenções que aumentem a efetividade das normas de saúde pública requer um conhecimento mais próximo da realidade, do dia-a-dia dos doentes, médicos e instituições de saúde ${ }^{7}$. A abordagem qualitativa do presente estudo decorre da necessidade de compreender os processos de trabalho, a relação entre profissionais e destes com a instituição e com os pacientes com TB. Estas relações apresentam aspectos não quantificáveis de natureza afetiva, social e política. Na metodologia qualitativa, ao invés de estudarmos o fenômeno em si, o objeto de estudo passa a ser entender o significado individual ou coletivo do fenômeno. Para Turato ${ }^{8}$, o significado tem função estruturante: em torno do que as coisas significam, as pessoas organizarão, de certo modo, suas vidas, incluindo seus próprios cuidados com a saúde.

As entrevistas com os médicos foram analisadas sob a ótica da fenomenologia hermenêuticadialética. A fenomenologia busca o conhecimento do mundo através da consciência do sujeito. Para Husserl ${ }^{9}$, considerado pai da fenomenologia, a consciência é uma atividade constituída por percepção, imaginação, especulação e paixão' . O contexto institucional, os processos de trabalho, as relações entre profissionais e com os pacientes, se constituem, para a fenomenologia, experiências da consciência e podem ser estudadas no discurso do sujeito ${ }^{10}$. Amatuzzi ${ }^{11}$ descreve duas tendências da pesquisa fenomenológica, uma empírica e outra hermenêutica. A empírica leva ao estudo do comportamento como um objeto do mundo físico e a hermenêutica objetiva compreender e interpretar o significado dos comportamentos humanos ${ }^{11}$. A partir destas tendências, constrói uma série de categorias de pesquisa, entre elas, a pesquisa fenomenológica-hermenêutica, e se apóia no esquema de Gamboa ${ }^{12,13}$ que propõe uma terceira que é a dialética. A dialética considera o comportamento em função dos seus determinantes sócio-históricos e contradições existentes na sociedade. A abordagem fenomenológica hermenêu- 
tico-dialética considera também a presença maior de subjetividade do pesquisador no contexto dialógico no qual se desenvolve a pesquisa.

\section{População e cenário de estudo}

Foram convidados a participar médicos de um dos dois hospitais públicos de grande porte com emergência aberta do município do Rio de Janeiro $^{7}$, em que realizamos recentemente um estudo sobre os óbitos relacionados à TB. Neste hospital são realizados cerca de 800 atendimentos/dia, entre os quais casos de TB pulmonar bacilífera, forma que transmite a doença, em condições inadequadas de infraestrutura e biossegurança ${ }^{7}$. A escolha deste cenário se deu por ocorrerem em hospitais 77\% dos óbitos por TB no Brasil ${ }^{14}$. Foram incluídos profissionais de diferentes faixas etárias, residentes e efetivos, de ambos os sexos. Os entrevistados tinham uma mediana do tempo de formatura de 24 anos (2 a 39 anos), especialização ou residência (completa ou em andamento) e estavam lotados na emergência (7), clínica médica (2) ou em ambos os setores (2). As entrevistas foram iniciadas em março de 2007 e encerradas em julho de 2007, quando foi considerada baixa a probabilidade do aparecimento de novos temas, o que constituiu uma amostra teórica ou por saturação de onze médicos ${ }^{15,16}$.

\section{Entrevista}

As entrevistas semiestruturadas foram conduzidas por uma das autoras (KG), gravadas e transcritas. As entrevistas foram realizadas em ambiente privativo visando à liberdade de expressão do entrevistado e o sigilo. As seguintes perguntas foram feitas:

Na sua opinião, por que morrem os pacientes com TB?

O que pode ser feito neste hospital para diminuir os óbitos por TB?

Qual a importância do serviço de Vigilância Epidemiológica para o seu trabalho?

Qual importância da Comissão de Óbitos para o seu trabalho?

Qual o sentimento que a morte de uma pessoa por TB lhe provoca?

Diante das respostas dos entrevistados, foram realizadas intervenções buscando reconduzir a discussão para o tema central e se aproximar dos sentidos do discurso para que fossem explicitados e desdobrados, numa atitude interativa. A atitude investigativa buscou aprofundar as infor- mações coletadas, de modo a tentar garantir uma abordagem significativa do assunto.

\section{Análise}

A análise do material transcrito das entrevistas visou encontrar as particularidades do discurso de cada profissional. Em seguida, a leitura do material teve como objetivo buscar os elementos comuns e as variantes dentro de cada entrevista e entre as entrevistas. Neste processo, a intenção foi captar a extensão e a intensidade (força) dos comentários e a qualidade dos mesmos (detalhamento e especificidade). Foram observadas também as falas que se diferenciaram, as contradições e as ambiguidades no discurso de cada participante e entre os mesmos.

Para sistematizar a análise destacamos as falas que expressaram o vivido em relação ao assunto da pesquisa e os relatos foram divididos em unidades de significado - as categorias ${ }^{17}$.

A interpretação teve o sentido de ultrapassar as falas espontâneas para se compreender a fala dos informantes a partir da contribuição de diferentes campos do conhecimento teórico. A discussão estabelece um diálogo dos sentidos resultantes da análise e da interpretação do resultado ${ }^{18}$. A conclusão tem como objetivo sugerir propostas de intervenções a partir da análise realizada.

O projeto foi aprovado pelo Comitê de Ética em Pesquisa da Secretaria Municipal de Saúde do Rio de Janeiro em 14 de março de 2005. Os profissionais entrevistados manifestaram sua concordância em participar através da assinatura do termo de consentimento livre e esclarecido.

\section{Resultados}

Três categorias foram identificadas nas falas dos depoentes: o abandono, a invisibilidade e o resgate. Dentre estas categorias, neste artigo vamos tratar de uma delas, "o abandono" que, em um efeito bumerangue, se apresenta com suas duas trajetórias que se opõem e expressam a vivência de, ora uma postura ativa, daquele que abandona, ora uma postura mais passiva, daquele que se sente abandonado.

Nessa categoria, as falas dos médicos nos revelam quatro dimensões: o respeito, a responsabilidade, as condições de atendimento e o malestar. Estas dimensões são vivenciadas por três atores: o sistema de saúde, o médico e o paciente. A fala abaixo retrata o conjunto das dimensões acima citadas. 
“... paciente com 29 anos, há 10 dias internado, desidratado, consumido e sem dieta. Não podia comer sozinho, dieta enteral prescrita há 48 h e nem o cateter tinha sido passado, portanto, sem medicamento para TB. Entubar? O colega, que aparece na porta sem vir ajudar, diz: '-Pensa na relação custo-benefício, olha o tamanho da fila...' ...olho para o acadêmico, vejo medo de pegar a doença, não tem máscara. A fila (hesitação) deveria estar toda no programa de saúde da família e não aqui. ... claustrofobia! Estou preso numa situação sem esperança, com culpa, peso na consciência ... Eu tenho 28 anos!!!”

O discurso dos profissionais, que prestam assistência a pacientes empobrecidos, num hospital "lotado", aponta para dificuldades que extrapolam às inerentes ao caso clínico. A fala acima reflete problemas específicos relacionados à $\mathrm{TB}$, como a gravidade dos pacientes que chegam à emergência e a questão da biossegurança ${ }^{7}$, e outros de ordem geral, que foram expostos pelos profissionais de forma contundente e que serão detalhados a seguir.

Em relação à dimensão respeito, as falas dos médicos nos revelam sua percepção de transgressões à Constituição Federal, às normas do Ministério da Saúde, ao Código de Ética Médica ${ }^{19}$, aos direitos do cidadão e entre os profissionais:

"Saúde é um direito de todos e um dever do estado, bonito no papel”.

"Não temos isolamento. Na enfermaria, quando internamos um bacilífero temos que tirar os pacientes dos outros leitos".

"... emergência: pega o gladiador bota na arena e diz: aí... se vira meu irmão".

“... em 1994, fiz um documento com problemas e sugestões. De lá pra cá, nada mudou. "Na intervenção (de 2005) teve o QUALISUS, trabalhei seis meses, no diagnóstico da situação. Diagramado, datashowzado, perfeito. Resultado: zero".

Denunciam o desrespeito ao paciente e à sua cidadania:

“... não tem onde cair morto, pois é, vem para cá para ter onde cair morto. Isso é tão importante (ter onde morrer), que elas (as pessoas) não se rebelam, aceitam qualquer coisa".

“... pobre, vítima social... moram na rua...”

“... estão na sarjeta, baixo poder de pressão aceitam qualquer coisa”

“... morreu um na ala LULA, um pimba: pobre, imundo, bêbado, atropelado; antes era ala FHC agora é Lula. Vêm da rua, caem e são trazidos. Enquanto não estiver atrapalhando na calçada, não estiver estendido na calçada, ninguém está ligando. Estendeu, vai morrer ali, aí man- dam o bombeiro recolher. Ameaça morrer e apodrecer na calçada de alguém... joga lá”.

"... Isso aqui é um micro de um macro. Os direitos do cidadão são violados e ninguém grita, todo mundo quietinho..."

"Quem quer saber de mendigo?"

Percebem também o desrespeito a si próprios:

"Desrespeitado, diariamente. Humilhado ... Descuido do sistema e do doente"

Um discurso destoa dos demais:

"Quanto mais desprotegido, mais me dá vontade de fazer pelo paciente".

$\mathrm{Na}$ dimensão responsabilidade, aparecem as percepções sobre as atribuições e o compromisso de cada um dos atores:

"O sistema de atribuições e responsabilidade é uma pirâmide: em cima a prefeitura do Rio, a secretaria, superintendência, hospitais, até chegar ao maqueiro e aos órgãos da sociedade civil, conselho e sindicato... Não existe responsabilidade, compromisso e sim, omissão criminosa. Se lá em cima a pessoa for sem compromisso, vão sendo escolhidos para dirigir os (gestores) que não dão trabalho - (que não questionam) o fio da meada começa no prefeito e vai até o maqueiro".

Uma das questões que aparece com força nesta dimensão é a da porta de entrada do paciente com TB no sistema de saúde. De quem é a responsabilidade de manter as portas abertas para o paciente? Os médicos entrevistados entendem que a emergência não é este local, que os pacientes deveriam procurar o atendimento nas unidades básicas de saúde:

"Todas as portas estavam fechadas, por isso (o paciente) vem para cá”.

"Aqui não é lugar de tuberculose. $\mathrm{O}$ atendimento aqui tem que ser rápido".

"(O paciente com TB) Está deitado aonde não deveria estar, ali é pronto socorro”.

"O sistema é desestruturado e ele (o paciente) vem para cá, (este paciente) é do posto, não do hospital".

Como se não bastassem as portas fechadas, o paciente ainda é responsabilizado pela sua condição:

“...descuido do doente... é desleixado".

"O doente não tem acesso, ele não quer acesso".

"Querem vir para cá tomar um remédio para febre, comida, são encaminhados para o posto, mas não vão... tem que chegar cedo, pegar senha, ele prefere que o pessoal faça tudo para ele..."

“... para o paciente, ter TB é lucro, vai ter casa e comida por duas semanas, quando ele enche o saco vai embora e volta quatro meses depois. 
Usa TB como um jogo. É assim que a população de rua usa o hospital".

Os médicos entendem que a procura dos serviços de emergência pelos pacientes com TB sobrecarrega as unidades hospitalares e as equipes, que já trabalham em condições de atendimento inadequadas no que diz respeito tanto à infraestrutura quanto aos recursos humanos. Em relação à infraestrutura, declaram:

"Paciente fica dias e mais dias na emergência em contato com toda população...”

"Na emergência, são 10 boxes e cada um com dois pacientes, máximo de 20 pacientes. Hoje estou com 34, três entubados e de madrugada eram nove".

“O hospital 'XX' é um arremedo do que já foi, o 'YY' está um horror, tenho vergonha de ir lá, de olhar".

"A nutricionista não tem balança. Avalia no olho".

Quanto aos recursos humanos, as condições de atendimento abrangem aspectos de remuneração, carga de trabalho, solidariedade, valorização e formação do profissional:

"Na sala de emergência você tem o dobro de paciente que você tem que ter com $1 / 3$ dos médicos que tem que ter. Um médico para fazer o serviço de seis, nunca vai sair bem feito".

"Falta investimento na pessoa (profissionais). O médico está largado há muitos anos”.

"A emergência nunca é treinada. Pouco tem se investido na pessoa".

"Medicamento até que tem, o que falta é o recurso humano. No sábado de noite, $12 \mathrm{~h}$, eu e eu! As pessoas falam: 'você é louco, porque não sai?' Estou aqui há quatro anos, gostaria de ficar, mas trabalhando como sei”.

Nessas condições de atendimento adversas, os médicos se ressentem da falta de solidariedade por parte das chefias e dos colegas:

"Eu estou querendo uma solução, estou querendo conserto. Uma chefia que diga: que droga..., mas a gente está tentando".

"O problema não chega até eles (chefia). Chefia deveria estar ali (emergência) e não está. Está na cadeira, com carimbo diferenciado".

"Não tem equipe... se a troca de plantão for às $8 \mathrm{~h}$ e tiver uma parada cardíaca, azar. Cada um toca o seu trabalho e fim de papo".

Por outro lado, algumas falas destoam:

"A diretoria ouve, não resolve, mas ouve".

"Você tenta não passar muitos problemas para o profissional que vai chegar (no plantão), mas não tem jeito, você vai passar".

O abandono também é retratado nas opini- ões sobre a remuneração.

“... governo finge que paga e o médico finge que trabalha”.

“... baixo salário ... jovens se afastam do SUS, me lembro do concurso, foi uma vitória... empregão, hoje é sobra da sobra."

"Trabalho gigantesco por mil reais, vai lá, vai lá dar plantão...”

"O produto final do nosso trabalho é muito barato".

Para além da remuneração, encontramos a desvalorização do médico:

"O médico não vê resultado do seu trabalho, tem que dar um atendimento que não é o que deve ser".

"Sem condições e sem salário. Sem valor. Largado..."

"os acadêmicos dizem você não devia vir, é um tapa buraco, louco de não largar isto daqui”.

O sentimento de abandono é acompanhado por um mal-estar que se manifesta por uma diversidade de afetos:

"Sinto vergonha, muita vergonha (da situação de trabalho, do hospital)...”

"Gente chegando e a sala abandonada... muita tensão".

"Desmotivação. Eu cheguei a chefiar um Centro de Saúde, pedi demissão, saí fora, não dava...”

"Desestímulo dos profissionais e auxiliares. Todos desmotivados".

"Eu vivo um momento amargo, da minha relação existencial com a vida. Não é com a vida institucional, é com a vida política, com a vida".

"... frustração, monte de frustrações, viver nesse país, ser cidadão desse país”.

“... frustração, um sentimento muito ruim de coparticipação com a mediocridade na medida em que não denuncia. Isso me chateia, estou errada”.

Em meio a essas inquietações afetivas, surgem reações para superá-las:

"Abandonei o Estado. Chegou um dia, peguei meu chapéu..."

"Eu me ilhei..."

"Todos (os pacientes) têm a mesma cara, o mesmo nome. É pra me defender do stress".

"Tristeza, é... mas... não fico... a gente aprende a separar os sentimentos, não é?...”

"Arranjei um cantinho abandonado e agora eu botei para funcionar. Só vejo aqueles (doze) doentes, eu me blindei, é meu reino encantado. Sou como o beija-flor que leva gotinhas d'água para o incêndio...”

Inversamente, alguns tornam-se apáticos diante da situação:

“... não sei por que a gente não grita, não 
reclama de nada”.

"aula sobre tuberculose, ninguém foi, desmotivação grande... todos fazem tudo correndo, grana..."

...ou pessimistas em relação ao futuro:

"No país que a gente vive hoje, o dia de amanhã vai ser sempre pior".

"Não tem perspectiva de melhora, saúde não é prioridade".

Duas falam contrastam, refletindo motivação:

"Aqui (hospital público), você cresce profissionalmente, (isto) é muito bom".

"É preciso motivação, no momento os residentes fazem isso com a gente. Eles são a chama, eles são a lenha”

Os pacientes também reagem, se defendem como podem, muitas vezes tornando-se agressivos, na visão dos médicos entrevistados:

"Eles (os pacientes) dizem 'eu pago o seu salário’. Ficam dizendo coisas assim...”

"Baixo poder de barganha, vão ficando agressivos (os pacientes)... (o paciente) cai em cima".

"População ignorante não sabe como se proteger e acredita que se protege vindo aqui (emergência), se demorar o atendimento resolve espancar todo mundo".

"Ele (o paciente) só ganha as coisas no grito se pedir recebe logo um não na cara, nasceu assim e vai ser assim até morrer. É assim ou a vida engole ele".

\section{Discussão}

Neste estudo, o discurso dos médicos nos confronta com diversas expressões do abandono, vivenciadas e exercidas por diferentes atores. Encontramos na afirmativa de Deslandes ${ }^{20}$ uma síntese que espelha o conteúdo das falas dos depoentes:

"A violência no cotidiano dos serviços de emergência assume múltiplas formas, como: condições vis de atendimento oferecidas à população; um modelo de atendimento que despersonaliza, ignora e coisifica o usuário; um processo de trabalho que impõe doses consideráveis de sofrimento aos seus trabalhadores; uma forma de interação entre profissionais e clientela, quando estes se tornam oponentes, algumas vezes chegando ao confronto corporal; reprodução de preconceitos e estigmas sociais que servirão, muitas vezes, de critérios seletivos para a qualidade da atenção dispensada.”

A tuberculose, cumprindo o seu papel de doença sentinela, neste estudo que se propunha inicialmente a estudar as vivências relacionadas ao óbito, permitiu a identificação de aspectos do trabalho médico conhecidos no dia a dia dos hospitais e que refletem problemas que extrapolam as particularidades da doença e nos remetem ao sistema de saúde e às relações com o poder. Esta situação foi reconhecida pelo Governo Federal, que, em março de 2005, decretou estado de "calamidade pública” e resultou na intervenção federal em seis hospitais do município ${ }^{21}$.

Dificuldades como demanda excessiva não são percebidas como um esforço solicitado num momento de crise, como ocorre durante uma epidemia, e sim como um desrespeito estabelecido no cotidiano do hospital. São referidas com sarcasmo, como expressão de crítica velada à situação, e quiçá, como defesa contra o sofrimento que a situação gera.

A remuneração dos médicos é referida como incompatível com o investimento exigido para a formação médica e com a responsabilidade e dificuldade de suas atribuições. Em todas as entrevistas, a questão do valor da remuneração aparece como motivo de percepção de desvalorização profissional e mais uma vez é tratada com ironia e revolta. $\mathrm{Na}$ economia capitalista, a remuneração espelha a importância e o status com que a sociedade reconhece o profissional. Os médicos, profissionais que têm um tempo médio dedicado à formação de cerca de oito anos ${ }^{22}$, são, para 0 Conselho Federal de Medicina (CFM),

"na sua imensa maioria, massacrados por gestores públicos, com salários aviltantes, o que vem provocando uma evasão sem precedentes da maior fonte de emprego médico do país, o SUS ${ }^{23}$.

Outra consequência dos baixos salários é o excessivo número de atividades e de carga horária dedicada ao trabalho, preocupante ao se considerar que a atividade envolve sofrimento humano e decisão sobre vidas que podem ser prejudicadas pelo cansaço. No Brasil, $82 \%$ dos médicos exercem até três atividades, com longa jornada de trabalho ${ }^{22}$. A política de recursos humanos do SUS em que se previa plano de cargos e salários jamais foi implementada ${ }^{24}$.

Para o exercício da medicina, o domínio da técnica é imprescindível, porém insuficiente isoladamente. Solidariedade, sensibilidade, empatia, acolhimento e compromisso são atributos fundamentais e fazem parte da expectativa da sociedade em relação ao médico. Esses são predicados que tornam o exímio técnico ou cientista, um cuidador. O cuidador, por sua vez, segundo Campos, necessita de "um ambiente e suporte capaz de lhes sustentar no exercício de suas funções", para que possa exercer sua função ${ }^{24}$. Ser 
cuidado, no caso do médico, inclui condições de trabalho favoráveis para que desempenhem suas atividades com segurança e efetividade. O ambiente inadequado ao trabalho, caracterizado por deficiência de infraestrutura, equipamento e recursos humanos, é um obstáculo para a prestação de serviços e compromete a relação dos profissionais entre si e com os usuários ${ }^{25}$. Em relação à gestão e à administração, as menções foram sempre percebidas como abandono e fonte de pressão, ao invés de aliança, no sentido de concorrer para a busca de soluções. Segundo Junqueira é necessário que os gestores atuem mais incisivamente na coordenação, avaliação externa e supervisão para estabelecer eventuais correções de rumo e estimulem a participação dos profissionais como sujeitos ativos ${ }^{26}$.

A importância da solidariedade entre profissionais, laço que une pessoas e que favorece o trabalho de uma equipe é reconhecida como um sentimento importante, mas vivenciada de formas distintas. As tentativas de cooperação esbarram no caos das condições de atendimento, frustrando gestores, médicos e pacientes.

Em maio de 2000, o Ministério da Saúde regulamentou o Programa Nacional de Humanização com o objetivo de promover uma nova cultura de atendimento à saúde ${ }^{27}$. Segundo Deslandes ${ }^{28}$, o objetivo seria "aprimorar as relações entre profissionais, entre usuários e profissionais e entre hospital e comunidade, visando à melhoria da qualidade e à eficácia dos serviços prestados por estas instituições”.

A julgar pelos depoimentos dos médicos, o referido programa não obteve resultados no hospital do presente estudo. Também não percebemos, pelos relatos, a implementação neste hospital das políticas de saúde do trabalhador do Ministério da Saúde.

Uma questão que os médicos enfatizam diz respeito à porta de entrada do paciente com $\mathrm{TB}$ no sistema de saúde. A restrição do horário e o tempo de espera para o atendimento na atenção básica, relatados como fatores que dificultam e até impedem o tratamento da tuberculose ${ }^{29,30}$, são também descritos como fatores que contribuem para o uso indevido da emergência, o que pode ter como consequência a demanda excessiva, referida pelos entrevistados ${ }^{31}$. Os médicos julgam que a emergência é um lócus inadequado para o atendimento à TB. Para o médico do hospital, o paciente com TB não é de sua responsabilidade e o hospital não está preparado para atendê-lo, já que compete à atenção básica. Porém, no Município do Rio de Janeiro, o progra- ma de saúde da família tem uma cobertura de apenas $10 \%$ da população, o que o torna uma porta de entrada virtual para o SUS ${ }^{32}$. De fato, apesar de a maior parte dos casos de TB poder ser conduzida na atenção básica, um hospital geral com emergência aberta deve estar adequado para receber todos os doentes que não tenham possibilidade de buscar outra entrada no sistema, por falta de acesso, ou por necessidade de atendimento imediato, como no caso de uma complicação da doença. Mas, as deficiências do hospital, em especial a de recursos humanos, geram intolerância com pacientes que não preencham os critérios de emergência e uma sensação de desrespeito com a missão e a vocação da instituição, sentimento que também foi identificado por O’Dwyers durante avaliação dos serviços hospitalares participantes do Programa QualiSUS $^{33}$. As falas dos médicos parecem retratar o desconhecimento da organização do SUS, que não prevê restrições a qualquer tipo de atendimento em emergências abertas, ou, no contexto de uma demanda excessiva, uma projeção de responsabilidades e atribuições para terceiros.

A falta de condições de trabalho interfere no prazer do exercício profissional, e é percebida como abandono do sistema de saúde e de seus profissionais, e possivelmente concorre para intensificar os sentimentos de abandono, de frustração, de desmotivação, de tensão, de conformismo e até de vergonha. Percebe-se então que os que vivenciam abandono deixam abandonados, constituindo um efeito bumerangue e gerando sentimentos e sensações de mal-estar.

Estresse, sofrimento e sobrecarga de trabalho, aliados a expectativas frustradas, são fatores predisponentes para a SB. A SB é constituída por sinais físicos, emocionais e mentais. A exaustão emocional abrange sentimentos de desesperança, solidão, depressão, raiva, impaciência, irritabilidade, tensão, diminuição da empatia e aumento de sentimentos negativos como raiva e impaciência. A exaustão mental envolve baixa satisfação e atitudes negativas com relação a si mesmo, ao trabalho e à vida em geral ${ }^{5}$. Muitos desses sintomas aparecem nas falas dos entrevistados. Outros estudos ratificam nossos achados. Em 2007, encontrou-se uma prevalência de 23\% de transtornos mentais comuns em médicos da emergência, Unidade de Terapia Intensiva e enfermaria de um hospital geral do SUS de Pernambuco ${ }^{34}$. Na descrição do cotidiano desses médicos, foram identificadas situações de desgaste emocional, múltiplos empregos como compensação a baixos salários e sensação de sobre- 
carga de trabalho, como as referidas pelos entrevistados do presente estudo. Uma meta-análise sobre trabalho e saúde envolvendo cerca de 500 estudos encontrou forte associação entre a satisfação com o trabalho e o bem-estar físico e men$\mathrm{tal}^{35}$. As falas aqui transcritas demonstram que o estado de ânimo dos profissionais do hospital de nosso estudo encontra-se também abalado. Apesar de não poderem ser imputadas exclusivamente à situação de trabalho, são preocupantes sob o ponto de vista de saúde mental.

Para lidar com tamanho desconforto, desenvolvem-se respostas muitas vezes defensivas. A descrição de Nogueira-Martins ${ }^{36}$ vem ao encontro do que ouvimos:

"Na SB, surge uma couraça impermeável às emoções e sentimentos, que se expressa por um embotamento emocional traduzido por uma aparente frieza no contato com os pacientes e com as pessoas de um modo geral. Um profissional que está burning-out, tende a criticar tudo e todos que o cercam, tem pouca energia para as diferentes solicitações de seu trabalho, desenvolve frieza e indiferença para com as necessidades e o sofrimento dos outros, tem sentimentos de decepção e frustração e comprometimento da autoestima".

Surgem também estratégias e busca de soluções individuais como tentativa de suprir a falta de planejamento e ordenação institucionais. Um dos entrevistados criou sua "Ilha da Fantasia", onde um grupo de médicos e enfermeiros cuida de determinados pacientes, desconsiderando a situação caótica do restante da instituição, parecendo procurar fazer "justiça com as próprias mãos". A motivação, quando presente, se origina pelo aprendizado decorrente do caos que instiga a busca de soluções e a orientação a residentes passa a ser o foco da atividade de profissionais da assistência. É provável que um sentimento de orgulho heróico seja o pano de fundo destas vivências.

Resta a interrogação de como indivíduos que se sentem abandonados, com profundo mal-estar em relação ao seu cotidiano de trabalho, os médicos cuidadores, possam cuidar de pacientes também abandonados. A relação com os usuários, população alvo deste sistema, na percepção dos médicos, é carregada de animosidade, estranha à idealizada relação médico-paciente. Neste momento, o paciente abandona seu reconhecimento e admiração pelo médico, o que nos remete, mais uma vez, ao efeito bumerangue.

Por outro lado, também percebemos que o paciente frequentemente é culpabilizado pela sua situação, a "vítima é sempre culpada". A tendên- cia de culpabilizar a vítima por não ter tomado precauções relativas à sua saúde é bastante comum. A culpabilização de indivíduos que vivem em condições bastante adversas é uma reação que não encontra justificativas lógicas ${ }^{37}$, embora eventualmente compreensível, pois permite projetar no outro a responsabilidade pela situação.

Nosso estudo encerra algumas limitações. As entrevistas não foram realizadas com o objetivo de avaliar a percepção do sistema de saúde ou a saúde dos médicos, mas as falas referentes a esses dois temas preencheram os critérios para compor uma categoria. Sinais de exaustão profissional ou burnout foram identificados, o que implica na necessidade de estudos com o objetivo de identificar a presença do dano, dada a sua consequência para a saúde dos profissionais, de suas famílias, assim como dos usuários do SUS. Da mesma forma, outras categorias profissionais precisam ser avaliadas com o mesmo objetivo. As inúmeras questões éticas implicadas no movimento de abandono necessitam ser aprofundadas.

\section{Conclusão}

Os achados predominantes do estudo trazem à luz problemas inerentes à sociedade como um todo, de ordem política e social, bem como do sistema de saúde e da saúde dos profissionais que o compõem. Entendemos que à ação de abandono do sistema de saúde, do profissional e do paciente corresponde uma reação igual em sentido contrário, no caso abandonar o sistema de saúde, os profissionais e o paciente, configurando o que chamamos de efeito bumerangue.

É possível que o problema central do SUS, além dos vinculados ao seu financiamento e à sua gestão, seja o de valorização do recurso humano. Consideramos que para além dos profissionais que "pensam" o SUS, quem "faz" o SUS são os sujeitos, que se relacionam diretamente com o usuário em suas práticas profissionais cotidianas. É preciso que esses profissionais não considerem natural a prática do abandono e do ser abandonado. À semelhança de outros grupos com baixa capacidade de luta pela preservação de seus direitos, os médicos devem ser alvo de ações que levem à reflexão sobre a sua situação e o seu real empoderamento. Controlar a TB, bem como alcançar os demais objetivos do SUS, envolve uma política de recursos humanos que responda às questões apresentadas. 


\section{Colaboradores}

L Selig, K Geluda, T Junqueira, R Brito e A Trajman participaram igualmente de todas as etapas de elaboração do artigo.

\section{Referências}

1. Malta DC, Duarte EC, Almeida MF, Dias MAS, Morais Neto OL, Moura L, Ferraz W, Souza MFM. Lista de causas de mortes evitáveis por intervenções do Sistema Único de Saúde do Brasil. Epidemiol Serv Saude 2007; 16(4):233-244.

2. Porto A. Representações sociais da tuberculose: estigma e preconceito. Rev Saude Publica 2007; 41(Supl. 1):43-49.

3. Ribeiro ACP, Miranda KCL. Vivência do paciente com tuberculose em co-infecção HIV/Aids. J bras aids 2006; 7(3):144-149.

4. Campos EP. Quem cuida do cuidador: uma proposta para profissionais de saúde. Petrópolis: Editora Vozes; 2005.

5. World Health Organization (WHO). Primary prevention of mental neurological and psichosocial disorders. Geneva: World Health Organization (WHO); 1998.

6. Trigo TR, Teng CT, Hallak JEC. Síndrome de burnout ou estafa profissional e os transtornos psiquiátricos. Rev psiquiatr clin 2007; 34(5):223-233.

7. Selig L, Guedes R, Kritski A, Spector N, Lapa e Silva JR, Braga JU, Trajman A. Uses of Tuberculosis mortality surveillance to identify programme errors and improve database reporting. Int J Tuberc Lung Dis 2009; 13(8):982-988.

8. Turato EG. Métodos qualitativos e quantitativos na área de saúde: definições, diferenças e seus objetivos. Rev Saude Publica 2005; 39(3):507-514.

9. Husserl E. Investigações Lógicas: sexta investigação: elementos de uma elucidação fenomenológica do conhecimento. São Paulo: Abril Cultural; 1980.

10. Deslandes SF, Gomes R. A pesquisa qualitativa nos serviços de saúde notas teóricas. In: Bosi MLM, Mercado FJ, organizadores. Pesquisa Qualitativa de Serviços de Saúde. Petrópolis: Vozes; 2004. p. 99-120.

11. Amatuzzi MM. Apontamentos acerca da pesquisa fenomenológica. Estud Psicol 1996; 13(1):5-10.

12. Gamboa SAS. A dialética na pesquisa em educação: elementos de contexto. In Fazenda I, organizador. Metodologia da Pesquisa Educacional. São Paulo: Cortez; 2008. p. 93-115.

13. Gamboa SAS. Pesquisa qualitativa: superando tecnicismos e falsos dualismos. Contrapontos 2003; 3(3):393-405.

14. Brasil. Ministério da Saúde. DATASUS. Informações de Saúde. Mortalidade [acessado 2009 dez 12]. Disponível em: http://tabnet.datasus.ov.br/cgi/tabcgi. exe?sim/cnv/obtRJ.def

15. Minayo MCS. O desafio do conhecimento: pesquisa qualitativa em saúde. $8^{\text {a }}$ ed. São Paulo, Rio de Janeiro: Hucitec, Abrasco; 2004.

16. Fontanella BJB, Ricas J, Turato ER. Amostragem por saturação em pesquisas qualitativas em saúde: contribuições teóricas. Cad Saude Publica 2008; 24(1):17-27.

17. Bardin L. Análise de Conteúdo. Lisboa: Ed 70; 1977.

18. Geluda K. Fatores para o não uso de preservativo masculino entre estudantes adolescentes da cidade do Rio de Janeiro [dissertação]. Rio de Janeiro (RJ): Núcleo de Ensino de Saúde Coletiva, Universidade Federal do Rio do Janeiro; 2005. 
19. Conselho Federal de Medicina. Código de ética médica. [acessado 2010 ago 27]; Disponível em: http:/ /www.portalmedico.org.br/novocodigo/integra.asp

20. Deslandes SF. Violência no cotidiano dos serviços de emergência hospitalar: apresentações, práticas, interações e desafios [tese]. Rio de Janeiro (RJ): Escola Nacional de Saúde Pública, Fundação Oswaldo Cruz; 2000.

21. Crise na saúde do Rio de Janeiro. O Globo [programa na Internet] 2005. 10 Mar. [acessado 2009 dez 06]. Disponível em: http://jornalnacional.globo. com/Telejornais/JN/0,MUL559222-10406,00-CRISE+ $\mathrm{NA}+\mathrm{SAUDE}+\mathrm{DO}+\mathrm{RIO} \cdot \mathrm{html}$

22. Carneiro MB, Gouveia VV, coordenadores. O médico e seu trabalho: aspectos metodológicos e resultados do Brasil. Brasília, (DF): Conselho Federal de Medicina; 2004

23. Barbosa GA, Andrade EO, Carneiro MB, Gouveia VV, coordenadores. A Saúde dos Médicos do Brasil. Brasília (DF): Conselho Federal de Medicina; 2007.

24. Campos FE, Pierantoni CR, Machado MH. Conferências de saúde, o trabalho e o trabalhador da saúde: a expectativa do debate. Cadernos RH Saúde [periódicos na internet] 2006 [acessado 2010 mar 12]; 3(1):8-12. [Introdução]. Disponível em: http:// bvsms.saude.gov.br/bvs/publicacões/cadernos_rh. pdf

25. Gusmão-filho FAR, Carvalho EF, Araújo Junior JLAC. Avaliação do grau de implantação do Programa de Qualificação da Atenção Hospitalar de Urgência (Qualisus). Cien Saude Colet 2010; 15(Supl.1): 1227 1238 .

26. Junqueira TS, Cotta RMM, Gomes RC, Silveira SFR, Siqueira-Batista R, Pinheiro TMM, Sampaio RF. As relações laborais no âmbito da municipalização da gestão em saúde e os dilemas da relação expansão/ precarização do trabalho no contexto do SUS. Cad Saude Publica 2010; 26(5):918-928.

27. Brasil. Ministério da Saúde (MS). HumanizaSUS Política Nacional de Humanização. Brasília [acessado 2010 jan 12]. Disponível em: http://portal. saude.gov.br/portal/saude/cidadao/visualizar_texto. $\mathrm{cfm}$ ?idtxt $=28345$

28. Deslandes SF. Análise do discurso oficial sobre a humanização da assistência hospitalar Cienc Saude Coletiva 2004; 9(1):7-14.
29. Figueiredo TMRM, Villa TCS, Scatena LM, Gonzales RIC, Ruffino-Neto A, Nogueira JA, Oliveira AR, Almeida SA. Desempenho da atenção básica no controle da tuberculose. Rev Saude Publica 2009; 43(5):825-831.

30. Belo MTCT, Selig L, Luiz RR, Hanson C, Luna AL, Teixeira EG, Trajman A. Choosing incentives to stimulate tuberculosis treatment compliance in a poor county in Rio de Janeiro state, Brazil. Med Sci Monit 2006; 12(5):PH1-5.

31. Carret MLV, Fassa AG, Domingues MR. Inappropriate use of emergency services: a systematic review of prevalence and associated factors. Cad Saude Publica 2009; 25(1):7-28.

32. Brasil. Ministério da Saúde. Departamento de Aten ção Básica. [acessado 2010 ago 28]. Disponível em: http://200.214.130.35/dab/historico_cobertura_sf/ historico_cobertura_sf_relatorio.php

33. O’Dwyer GO, Oliveira SP, Seta HM. Avaliação dos serviços hospitalares de emergência do Programa QualiSUS. Cien Saude Colet 2009; 14(5):1881-1890.

34. Cabana MCFL, Ludermir AB, Silva ER, Ferreir MLL, Pinto MER. Transtornos mentais comuns em médicos e seu cotidiano de trabalho. J Bras Psiquiatr 2007; 56(1):33-47.

35. Faragher EB, Cass M, Cooper CL. The relationship between job satisfaction and health: a meta-analysis. Occup Environ Med 2005; 62(2):105-612.

36. Nogueira-Martins LA, Saúde Mental dos Profissionais de Saúde. Rev Bras Med Trab 2003; 1(1):56-58

37. Fortes PAC, Zoboli ELCP, organizadores. Bioética e Saúde Pública: entre o individual e o coletivo. In: Fortes PAC, Zoboli ELCP, organizadores. Bioética e Saúde Pública. São Paulo: Editora do Centro Universitário São Camilo; 2003. p. 11-24.

Artigo apresentado em 10/09/2010

Aprovado em 16/11/2010

Versão final apresentada em 30/11/2010 